\title{
Cicadas (of Florida), Neocicada hieroglyphica (Say), Tibicen, Diceroprocta and Melampsalta spp. (Insecta: Hemiptera: Cicadidae) ${ }^{1}$
}

Thomas J. Walker and Thomas E. Moore ${ }^{2}$

\section{Introduction}

In Florida, cicadas are best known for their loud calls heard during the day, usually issuing from trees. Their cast nymphal skeletons are often seen on the trunks of trees or on shrubs. In much of the eastern United States, they are also known for their appearance in colossal numbers (as many as 1.5 million per acre) every 13 or 17 years. Although these periodical cicadas (Magicicada spp.) do not occur in Florida, they merit further discussion under Life Cycles.

\section{Identification}

Cicadas are often heard but seldom seen or captured, so it is fortunate that species can be readily identified by their songs. The songs of most Florida species are at http://buzz.ifas.ufl.edu/c700fl1.htm. Morphological keys to genera of adults and of last instar nymphs and cast nymphal skeletons are at http://buzz.ifas.ufl.edu/c700kg.htm and http://buzz.ifas.ufl.edu/c700kg2.htm respectively.
The 19 cicada species known from Florida fall into three groups based on overall size as revealed by the length of the forewings:

\section{Small (length of forewing less than $7 \mathbf{~ m m}$ )}

- Melampsalta calliope (Walker) - little brown cicada

- Melampsalta floridensis Davis - little green cicada (Figure 1)

Medium (length of forewing 23 to $32 \mathrm{~mm}$ )

- Diceroprocta bequaerti (Davis) - Bequaert's cicada. Westernmost Panhandle; song a continuous buzz, ticks irregularly when approached.

- Diceroprocta olympusa (Walker) - Olympic cicada. Partial to pines and waste fields; song a continuous droning buzz.

- Diceroprocta viridifascia (Walker) - seaside cicada. Coastal; song a continuous slower and louder zit zit zit zit.

1. This document is EENY-327, one of a series of Featured Creatures from the Entomology and Nematology Department, Florida Cooperative Extension Service, Institute of Food and Agricultural Sciences, University of Florida. Published: May 2004. Revised: September 2004. This document is also available on Featured Creatures Website at http://creatures.ifas.ufl.edu. Please visit the EDIS Website at http://edis.ifas.ufl.edu. Additional information on these organisms, including many color photographs, is available at the Entomology and Nematology Department website at http://entnemdept.ifas.ufl.edu/. 2. Thomas J. Walker, Department of Entomology and Nematology, University of Florida, Gainesville and Thomas E. Moore, University of Michigan.

The Institute of Food and Agricultural Sciences (IFAS) is an Equal Employment Opportunity - Affirmative Action Employer authorized to provide research, educational information and other services only to individuals and institutions that function without regard to race, creed, color, religion, age, disability, sex, sexual orientation, marital status, national origin, political opinions or affiliations. For information on obtaining other extension publications, contact your county Cooperative Extension Service office. Florida Cooperative Extension Service / Institute of Food and Agricultural Sciences / University of Florida / Larry R. Arrington, Interim Dean 


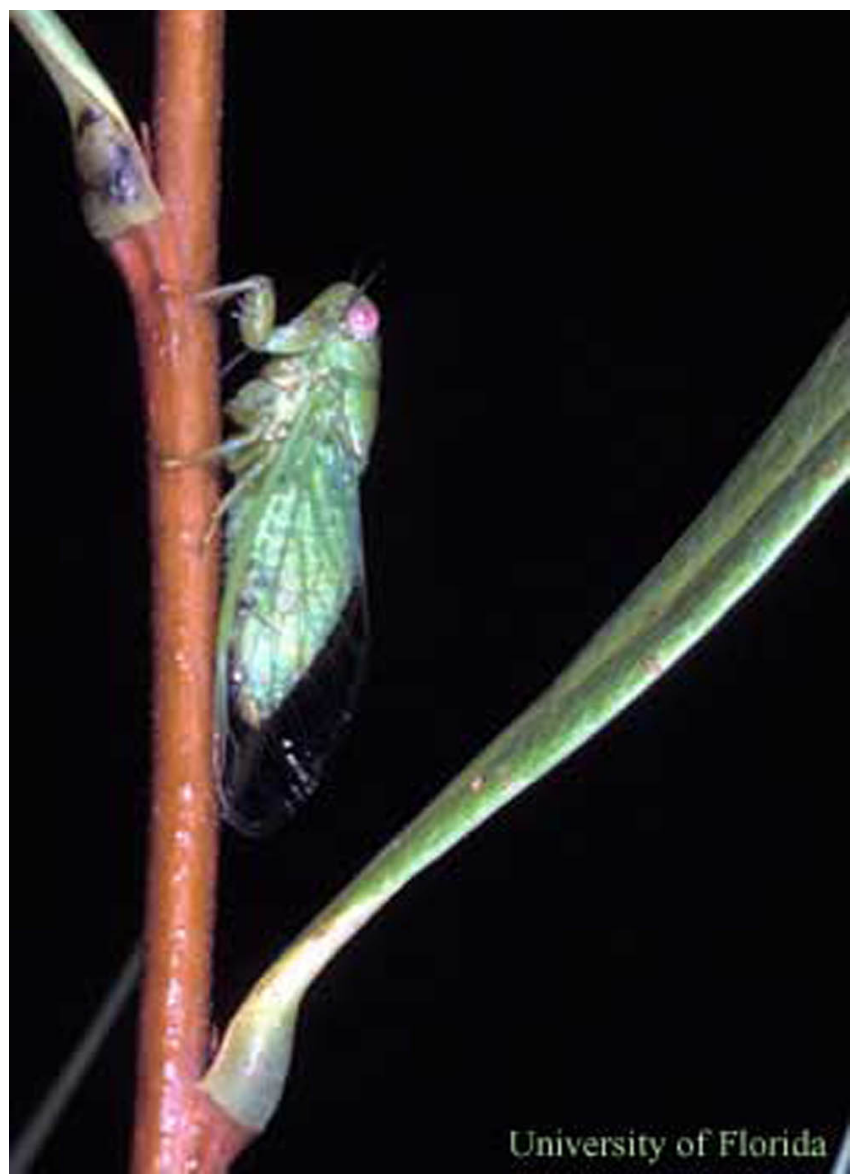

Figure 1. Little green cicada, Melampsalta floridensis Davis. Total length (head to tips of forewings) is $19 \mathrm{~mm}$ (about 3/4 inch). Credits: Photograph by: Lyle J. Buss, University of Florida

- Diceroprocta vitripennis (Say) - glass-winged cicada, Panhandle; partial to oaks; song a continuous faster and softer zit zit zit zit.

- Neocicada hieroglyphica (Say) - hieroglyphic cicada. Partial to oaks; first species to be heard in spring; song starts with a sequence of progressively softer whiney bursts and ends with an even whine. (Figure 2)

\section{Large (length of forewing 31-57 mm)}

- Diceroprocta biconica (Walker) - Keys cicada. Keys and Everglades; song a loud continuous high-pitched buzz.

- Tibicen auletes (Germar) - dusk-calling cicada•

- Tibicen canicularis (Harris) - dog-day cicada (Figure 3)

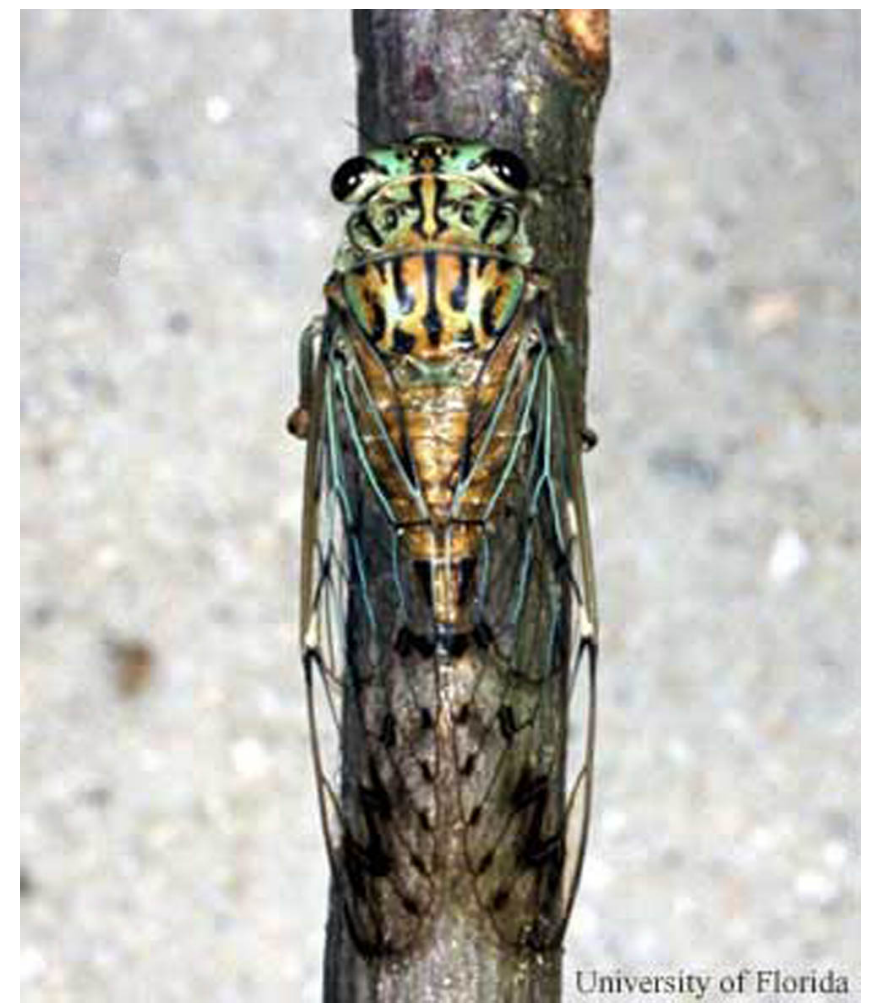

Figure 2. Hieroglyphic cicada, Neocicada hieroglyphica (Say). Total length (head to tips of forewings) is $32 \mathrm{~mm}$ (about 1 1/4 inch). Credits: Photograph by: Lyle J. Buss, University of Florida

- Tibicen chloromera (Walker) - swamp cicada

- Tibicen davisi (Smith and Grossbeck) - Davis's dog-day cicada

- Tibicen figurata (Walker) - fall dog-day cicada

- Tibicen linnei (Smith and Grossbeck) - Linne's cicada

- Tibicen lyricen (DeGeer) - lyric cicada

- Tibicen marginalis (Walker) - marginate cicada

- Tibicen pruinosa (Say) - scissor-grinder cicada

- Tibicen resonans (Walker) - resonate cicada

- Tibicen similaris (Smith and Grossbeck) similar cicada

\section{Sound Production}

Cicadas produce their calls with timbals ${ }^{1}$, which are paired drum-like structures on the sides of the basal abdominal segments. Each timbal is an area of 


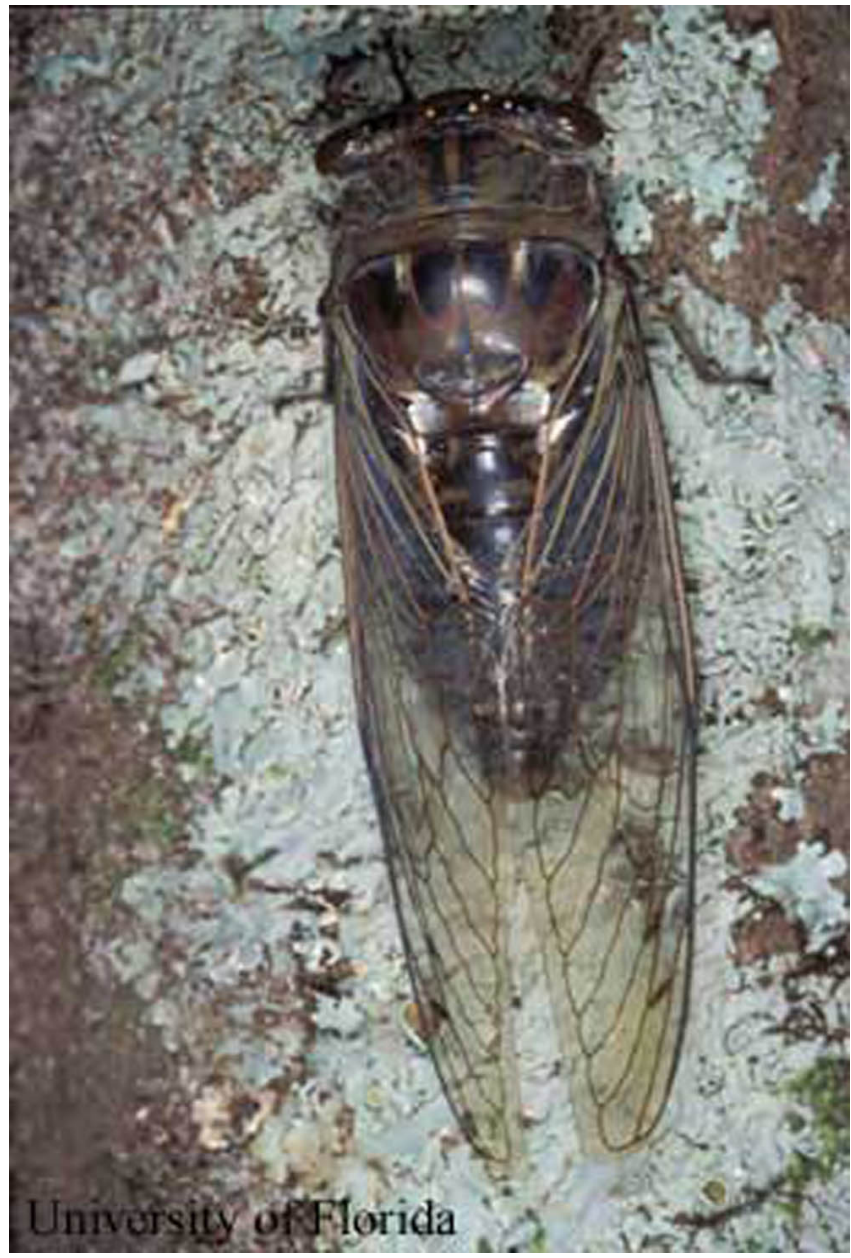

Figure 3. Dusk-calling cicada, Tibicen auletes (Germar). Total length (head to tips of forewings) is $64 \mathrm{~mm}$ (about 2 $1 / 2$ inches). Credits: Photograph by: Lyle J. Buss, University of Florida

flexible cuticle surrounded by a stiff rim and crossed top to bottom by a series of narrow stiff ribs and a stiff larger plate posterior to the ribs. A muscle that is attached to the timbal plate via a cuticular rod causes the timbal ribs to pop inward when it contracts and allows the ribs to pop outward when it relaxes. In some cicadas the timbal produces a loud sound when moving both in and out; in others only when moving inward. Internally each timbal is backed by an air sac that frees it to vibrate with each pop of its ribs. In most species the timbals are within chambers produced by cuticular extensions of the thorax and abdomen, and the sounds are modulated by control of the chambers' lower openings. The hearing organs of cicadas (tympana) share the same air sacs as the timbals and lie below them in the abdomen.
Note $^{1}$. A sound-producing organ of a cicada may be spelled either timbal or tymbal. We use the former because it avoids potential confusion with tympanum, which is used for insect hearing organs, and because timbales (not tymbales) refers to two single-headed drums played as a pair.

Only males have timbals (except for one Australian genus). Female cicadas are mostly mute (in the western United States, some females signal acoustically by wing tapping or stridulating). All cicadas can produce soft sounds with wing flips, and often do so in mild disturbance situations. Most sounds made by males are calling songs, which are species specific and serve to attract conspecific, sexually responsive females to the calling male. When a predator, such as a bird or small mammal, seizes or attempts to seize a male cicada, the cicada emits a protest song or disturbance squawk, which may startle the predator into allowing the squawker to escape. In some species, when a male is in visual or physical contact with a female, he emits quieter courtship songs. Females of several species are known to answer a courting male with wing flips that encourage the male.

Some cicada calling songs are reminiscent of noises made by power tools, which may account for occasional reports by homeowners and contractors that cicadas are attracted to their lawnmowers and outdoor power saws. The fact that attracted cicadas are invariably female supports this explanation. (Some cicadas, especially females, are also attracted to lights at night.)

\section{Life Cycles}

All cicada nymphs live in underground burrows, where they feed on xylem sap from roots of grasses, forbs, or woody plants. Xylem sap is low in nutrients, which helps account for the minimum duration of nymphal development being several years. All cicadas molt four times underground. When the last nymphal instar is ready to molt, it makes its way to the surface, climbs a short distance up a tree trunk or herb stem, anchors itself with its tarsal claws, molts for the fifth time, and becomes an adult (Figure 4). Its nymphal shell remains as evidence of its transition from a confined life underground to aerial freedom. 
Adult cicadas are strong fliers and visually alert. Most species spend their lives in trees, where males call, males and females mate, and females lay their eggs by inserting them into the woody tissue of small branches. Some cicadas feed on and lay eggs primarily in grasses and forbs. Adults regularly feed on xylem sap both by day and at night, but are short-lived, seldom living more than a few weeks.

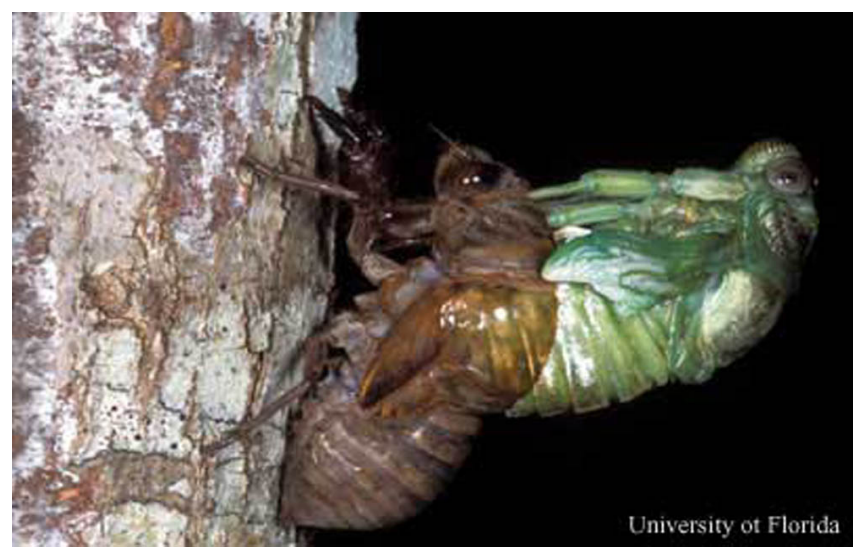

Figure 4. Cicada (Tibicen sp.) escaping its nymphal skeleton. The cast skeleton will remain attached to the tree. Once free, the adult will expand its wings, darken, and fly away. Credits: Photograph by: Lyle J. Buss, University of Florida

Females of the loudest-singing, tree-inhabiting cicadas whose males have completely concealed timbals lay their eggs in dead twigs where they remain until they hatch the next year. Females of many cicadas whose males have exposed timbals lay their eggs only in living twigs or branches and their eggs hatch the same year as laid. When cicada eggs hatch, the tiny, pale, ant-size nymphs fall to the ground, burrow downward via crevices, find a rootlet to feed upon, and begin their long underground lives.

Little is known about the length of their stay underground, except that the minimum seems to be four years under natural conditions - as determined for a small, grassland species. (In some small cicadas feeding on nitrogen-enriched crops in continuously warm areas, two-year life cycles have been reported.) Life cycles of woodland cicadas are longer and those of large woodland species, such as Tibicen spp., may be ten years or more.

The longest known life cycles for cicadas are 13 and 17 years. These life cycles occur in populations of periodical cicadas (Magicicada spp.), which are medium-size, woodland cicadas that emerge from the ground in massive numbers every 13 or 17 years. These mass emergences at intervals of more than a decade reminded early American settlers of biblical plagues of locusts - which were grasshoppers that chewed up leaves and did not suck sap. To these settlers, cicadas became known as "locusts," and that name for cicadas still endures in some localities. The massive, periodical emergences establish 13 and 17 years as the durations of Magicicada life cycles, but it must be noted that Magicicada populations in different parts of North America belong to different broods, which emerge in different years (as they maintain their rigid 13 and 17 year cycles). Only 12 of the 17 possible broods of 17-year cicadas actually exist, and for 13-year cicadas there are only three extant broods. The broods of periodical cicadas that occur closest to Florida have 13-year life cycles and are in southeastern Louisiana (next emergence, 2014) and in central Alabama and Georgia (next emergence, 2011).

Unlike the broods of periodical cicadas, populations of Florida cicadas produce adults every year. Even though Florida species emerge as adults annually, their life cycles surely require more than one year. In fact, the larger woodland species (Tibicen spp.) seem likely to require many years (at least a decade?), though no one has yet determined exactly how long the nymphs of any species of Tibicen remain underground. For species of cicadas that do not depend on mass emergences to overwhelm their predators, there is little reason to believe that the duration of underground development is set for a given number of years. Thus the progeny of the adults that mate and lay eggs in any one year seem likely to appear in a number of future "year classes" beginning no sooner than some minimum number of years, determined by nymphs that develop under the most favorable circumstances.

Cicadas of the genus Tibicen are sometimes termed "dog-day" cicadas, because in the north these species are heard every year in mid to late summer, the so-called dog days. In Florida some species of Tibicen begin calling in late spring and others do not start until September and call throughout the fall. 


\section{Economic Importance}

Cicadas are seldom of economic importance in Florida. In the past, Tibicen davisi occasionally caused severe damage to asparagus fern (Asparagus plumosus) grown in ferneries for use by florists (Wilson 1930a, 1930b). Numerous nymphs feeding on the roots greatly reduced the yield or even killed the plants. When the adults emerged, they flew to nearby woods to mate, and the females returned to the ferneries where they laid their eggs in the supporting timbers. No such damage has been reported in recent years, perhaps because Asparagus virgatum, which replaced A. plumosus as the crop grown in Florida ferneries, is less susceptible.

Adults of Diceroprocta viridifascia were once reported causing economic harm in another manner: their raucous daytime chorus interfered with a movie company's sound track for scenes it was filming at a beach near St. Augustine.

When cicadas oviposit in the twigs of trees, the twigs sometimes break and the leaves beyond the break die. This results in brown "flags" near the ends of branches in otherwise green trees. Such flagging is rarely reported in Florida but can severely damage northern orchards in the aftermath of emergences of periodical cicadas.

On the positive side, it should be noted that cicadas do not bite or sting and harbor no organisms known to be harmful to vertebrates. They provide food for many kinds of wildlife, including birds, small mammals, and other insects. Newly emerged adults are easily caught and have been used for food by humans, either raw or cooked, and are even credited with having saved some family groups from starvation early in the history of North America.

\section{Selected References}

Alexander RD, Moore TE. 1962. The evolutionary relationships of 17-year and 13-year cicadas and three new species (Homoptera, Cicadidae, Magicicada). Miscellaneous Publications of the University of Michigan Museum of Zoology 121: 1-59.
Beamer RH. 1928. Studies on the biology of Kansas Cicadidae. University of Kansas Science Bulletin 18: 155-263.

Cooley J, et al. (2004). Cicada Central: North America. http://collections2.eeb.uconn.edu/ collections/cicadacentral/NA/ (17 May 2004).

Cooley J, Marshall D. 2000. Michigan cicadas. Museum of Zoology, the University of Michigan. http://insects.ummz.lsa.umich.edu/fauna/ Michigan_Cicadas/Michigan/(17 May 2004).

Walker TJ, Moore TE. (2004). Singing insects of North America. http://buzz.ifas.ufl.edu/ (17 May 2004).

Wilson JW. (1930a). Cicadas severely damaging Asparagus plumosus. Florida Entomologist 4: 41-44.

http://palmm.fcla.edu/ fdl/cgi-bin/fdlcgi/ ZKVIEWEN00154040/pdf/_14/_3/_file318.pdf (17 May 2004).

Wilson JW. (1930b). Tibicen davisi Smith and Grossbeck (Cicadidae), a new pest of economic importance. http://palmm.fcla.edu/ fdl/cgibin/fdlcgi/ZKVIEWEN00154040/pdf/_14/_4/ _file1.pdf (17 May 2004). 